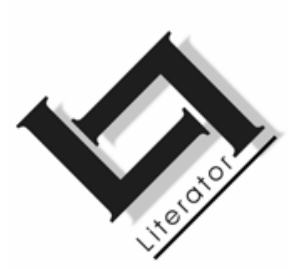

\title{
Onderwysstudente se parodieë as hibridiese tekste: 'n navorsingsverslag
}

\author{
Estelle Kruger \\ Kurrikulumstudies \\ Fakulteit Opvoedkunde \\ Universiteit van Stellenbosch \\ STELLENBOSCH \\ E-pos: ekruger@sun.ac.za
}

\begin{abstract}
Parody as hybridic text: research report

Parody can be seen as one of the techniques of selfreferentiality through which a consciousness of the context dependency of meaning is revealed in an aesthetic way. This article explores the theoretical background of parody as literary style against which the researcher challenged a group of teacher education students in a research programme to generate their own parodies. The task required that they choose a well-known fairy tale and use its structure to mock their own society. Students of another group were asked as the writers' peers to read the stories in order to engage in a dialogue between encoder and decoder in the process of reception.
\end{abstract}

The educational aim of the programme was to equip students to reflect critically and react creatively to social, political and economic issues that surround them. Furthermore, the researcher wanted to discover how these texts would generate a flexibility, fluency and hybridity in relationship with the students' cultural identity and how they would project their own liminality in a no-man's land between youth and adulthood.

Analysis and interpretation of the parody texts revealed themes of late capitalism, materialism and consumerism, as well as typical student cultural manifestations of language usage and some of their existing attitudes toward the South African political society in post-apartheid. The students' parodies have intertextual density with imitation and subversion of the original text contexts and values. The writers used a variety of stylistic 
techniques to generate double-voiced narratives as manifestation of literary creativity.

\section{Opsomming}

\section{Onderwysstudente se parodieë as hibridiese tekste: 'n navorsingsverslag}

Parodie kan gesien word as een van die tegnieke van selfreferensialiteit waardeur die outeur se bewussyn van die kontekstuele afhanklikheid van betekenis estetiese vergestalting vind. Hierdie artikel verken die teoretiese agtergrond van parodie as literêre styl, sowel as die navorser se bevindings van 'n navorsingsprogram waarbinne 'n groep onderwysstudente uitgedaag is om hul eie parodietekste te genereer. Die taak was om 'n bekende sprokie te kies en die struktuur daarvan te gebruik om met die samelewing te spot. 'n Ander groep studente het in die navorsingsprogram as portuurlesers opgetree, om deur die lees van die nuwe parodieë in 'n dialoog tussen enkodeerder en dekodeerder te tree.

Die opvoedkundige doelwit van die onderrigprogram wat deel van die navorsingsprogram was en waarvan verslag gelewer word, was om onderwysstudente toe te rus om krities te reflekteer en kreatief skrywend te reageer op sosiale, politieke en ekonomiese kwessies wat hulle omring in die samelewing. Verder wou die navorser ontdek hoe hierdie kreatiewe skryfpogings buigsaamheid, vlotheid en hibriditeit in verhouding tot die studente se kulturele identiteit uitbeeld.

Die analise en interpretasie van die parodietekste het verskeie temas van laat-kapitalisme, materialisme en 'n verbruikersamelewing aangetoon, sowel as tipiese studentekulturele manifestasies van taalgebruik en bestaande houdings teenoor die Suid-Afrikaanse sosiaal-politiese samelewing in postapartheid. Die studente se parodieë het intertekstuele digtheid getoon, met nabootsing en omkering van die oorspronklike tekste se kontekste en waardes. Uiteindelik het die studente as outeurs 'n verskeidenheid stilistiese tegnieke gebruik om dubbelstemmige narratiewe te skep.

\section{Agtergrond van die navorsingsprogram}

$\ldots$ en daar is glad niks nuuts onder die son nie ... (Pred. 1:9)

Tydens 'n navorsingsprogram in 2004 het 'n groep van dertien nagraadse onderwysstudente die taak gehad om parodietekste uit bekende sprokies te skep - sprokies wat ten nouste verweef is met hulle eietydse massa- en studentekultuur. Eers is hulle blootgestel 
aan bestaande sprokieparodieë (Dahl \& Blake, 1982; Garner, 1994; De Vos \& Grobler, 1999) en die elemente van parodie as stylfiguur is aan hulle voorgehou (Band, 1990; Pretorius, 1992a). Met hierdie opdrag wou ek vasstel in watter mate daar in die tekste wat die studente op hierdie manier genereer, getuienis is van vloeibaarheid, veelvoudigheid en hibriditeit wat in verhouding is tot hulle kulturele identiteit (vgl. Johnston \& Mangat, 2003:200).

Die opdrag het soos volg gelui:

- Kies 'n bekende ou sprokie en verander die karakters, ruimte en tyd soos wat jy wil;

- $\quad$ sit hierdie dele aanmekaar en skep 'n parodie met 'n intrige wat pas in die konteks van jou huidige samelewing;

- $\quad$ spot in jou parodie met die samelewing soos wat jy wil.

Die doel met die onderrigprogram was dat hierdie studente toegerus moet word om te reflekteer en krities te reageer op letterkunde, kuns en kultuur, sowel as sosiale, politieke en ekonomiese sake. Op hierdie manier kon die program daartoe bydra dat die studente as kritiese denkers in hulle eie samelewing ontwikkel. Hierdie program was in aansluiting by Hutcheon (1985:85) wat parodie beskou as een van die tegnieke van selfreferensialiteit waardeur 'n bewussyn van die konteks-afhanklikheid van betekenis op estetiese wyse geopenbaar word. Hutcheon meen dat die omstandighede wat enige uiting omring 'n belangrike deel van die betekenisgewing uitmaak. Dit was moontlik om met vyf van die parodieskrywers 'n opvolggesprek te voer. Al was die bedoeling nooit om literêre kunswerke te skep nie, was die dialogiese interaksie tussen skrywer en leser en die tydgebondenheid van hierdie tekste bepalend vir die lees, begrip en genot daarvan.

Hutcheon (1985) beklemtoon die waarde van die leser se resepsie in die dekodering van die outeur se enkodering. Dit is dus nie net die produksie van parodietekste wat belangrik is in die navorsingsprogram nie, maar ook die resepsie daarvan. As deel van die navorsingsprogram het ek dus ook onderhoude gevoer met vyf portuurlesers (bruin en wit, dame- en manstudente, almal Afrikaanssprekend) om te bepaal watter breë kulturele (en meer spesifiek: kampuskulturele) projeksies hulle in die stories gevind het.

In hierdie artikel sal ek die skepping van parodieë as hibridiese tekste in liminale ruimtes teoreties verken en verslag lewer oor die mate waarin die studente se parodietekste wel tekens van kruiskulturele en intertekstuele hibriditeit toon. Vervolgens is dit eers 
nodig om opmerkings te maak oor enkele relevante konsepte wat rigting gee aan die begrip van die betekenis en sinvolheid van die navorsingsprogram in kulturele konteks.

\section{Die parodie as kulturele teks}

\subsection{Omskrywing van parodie}

Omdat parodie deel uitmaak van 'n reeks metakulturele praktyke (Van der Merwe, 2004:11) en moeilik definieerbaar is, sal ek vir die doel van hierdie artikel volstaan by Dentith (2000:9) se breë omskrywing dat parodie enige kulturele praktyk insluit wat 'n relatief polemiese nabootsing van 'n ander kulturele produksie of praktyk is.

'n Teoretikus wat breedvoerig skryf oor die kenmerke van die parodie as satiriese styl, Margaret Rose (1979; 1993), bespreek intensief die geskiedenis van literêre parodie se klassieke wortels (Grieks: para = dubbelstemmigheid; Latyn: parodia $=$ neffens, heterogeen, ongelyksoortig) en die waarde daarvan in veral die twintigste-eeuse modernisme en postmodernisme. Naas Rose se insiggewende werke lewer ook Linda Hutcheon (1985) 'n pleidooi, enersyds vir 'n breër respek vir die pragmatiese kompleksiteit van parodie in sowel twintigste-eeuse skryf- as visuele kuns (ook argitektuur) en musiek, en andersyds vir 'n kritiese respons wat die komplekse aard van estetiese realiteite respekteer.

'n Parodie kan breedweg gesien word as 'n satiriese narratief en woordspel om waardes en gebruike te relativeer (vgl. Vosloo, 2003:90-95). Die humortegnieke wat in die parodie as stylfigure gebruik word, is veral satire en ironie. Pretorius (1992b:465) noem as satiriese wapens: geestigheid (wit), sarkasme, ironie, sinisme, paradoks, antitese, burleske en skeldtaal. Walters (aangehaal in Vosloo, 2003:71) noem ook verwringing, oordrywing, jukstaposisionering van ongelyksoortige dinge, litotes, hiperbool, reduksie of ontluistering, bespotting, inversie, gevatheid, aanhalings en intertekstualiteit. Dit sluit aan by Rose (1993:97) se lys van spesifieke tegnieke wat 'n parodieskrywer gebruik om 'n oerteks te parodieer: karikature, vervanging, toevoeging, aftrekking, oordrywing, kondensasie, naasmekaarstelling en inkongruensie. Hierby kan ook stereotipes gevoeg word.

'n Opsomming van die vernaamste kenmerke van verwante vorme van die parodie, soos wat in hierdie navorsing na vore gekom het, is die volgende (Shipley, 1972; Grové, 1976; Rose, 1979; Hutcheon, 
1985; Conradie, 1992; Pretorius, 1992a; Rose, 1993; Annesley, 1998; Dentith, 2000; Verster, 2003; Vosloo, 2003):

- 'n Parodie is letterlik 'n belaglikmakende, satiriese newelied, waar die ernstige aard of implikasie van 'n bestaande literêre werk of konvensie deur middel van 'n klugtige, lagwekkende nabootsing tot die absurde herlei word. Kenmerkend is die dubbelgerigtheid om met bedekte spot te ontveins en te hervorm. Dit is gebaseer op tegnieke van verwringing, oordrywing en die ironiese bymekaarbring van ongelyksoortige dinge. Verskillende soorte kan gevind word, onder andere verbale, formeel-stilistiese en tematiese variante.

- 'n Burlesk(e) is 'n klugtige, komieklike voorstelling en fyn bespotting van die samelewing se norme en instellings deur ironiese oordrywing (selfs die groteske); 'n spottend-ironiese nabootsing op so 'n wyse dat die banale oordrewe groots en die verhewene belaglik voorkom. Ernstige voorstellings word op 'n karikatuuragtige wyse nage-aap. Die taalgebruik is ru-grappig, plat-komies en skertsend en die komiese effek word geproduseer deur 'n doelbewuste wanverhouding tussen styl en sentiment.

- 'n Pastiche is ' $n$ samevoeging van uiteenlopende elemente ter wille van satiriese effek, met onoordeelkundige ontleding op so 'n wyse dat die geleende elemente nie altyd struktureel opgaan in die nuwe verband nie. Dit kan ook gesien word as 'n bedrieglike nabootsing van 'n literêre teks wat gemaak word deur die aanmekaarskakeling van ' $n$ mengelmoes beelde en episodes oorgeneem uit verskeie tekste of kontekste. Hier kom dikwels karikaturale oordrywing voor en dit is duidelik 'n nabootsing van 'n ander werk.

- 'n Melodrama is die verwerking van romans of ander oorspronklike literêre tekste waar die karakters stereotiep is en weinig kompleksiteit toon. Die intrige het baie uiterlike handeling met sensasionele insidente wat losweg aan mekaar gevoeg is. Deur oordrywing word klem gelê op patetiese of aandoenlike aspekte, oordrewe dialoog en skouspelagtige situasies. Daar is ' $n$ duidelike strewe om op die gevoelens van die toeskouer (en leser) te speel en so reaksie te ontlok.

In verband met die aktiewe rol wat satire as voertuig in kreatiewe skryfwerk kan speel, gee Reeves (1996) verslag van die toenemende mate waarin haar studente se kritiese bewustheid ontwikkel het deur die skryf van parodieë om te spot met eietydse konflikte met hiërargiese strukture en gewaande morele superioriteit. 
Reeves maak melding van die filosoof Kierkegaard se konsep van negatiewe vryheid, waar die studente deur middel van die kreatiewe gebruik van ironie en inversie vrygemaak word van eietydse belaglike konvensies en onderdrukking waaraan hulle blootgestel is. Sy meen dat kritiek wat met humor gekombineer is 'n uitlaatklep bied vir frustrasie, sonder die vrees vir vergelding of direkte aanvalle. Volgens Reeves is die bonus van dié skryfoefening dat haar studente deur middel van nabootsing sensitief geword het vir die effekte van linguistieke keuses wat betekenis en perspektief betref, en dat hulle ook meer bewus geraak het van die verskille tussen die taal van die oorspronklike teks en hulle eietydse gebruik daarvan. Hierdie bevinding van Reeves stem ooreen met die rol wat die parodieë speel in die kulturele oorgangsruimtes (liminaliteit) waarin die studente as skrywers en lesers in my navorsingsprogram woon.

\subsection{Liminaliteit met betrekking tot studente}

Victor Turner (in navolging van A. van Gennep se The rites of passage, 1960) gebruik die term liminaliteit om die vestiging van identiteit te beskryf. Identiteite ontwikkel soos wat dit in oorgangsruimtes plaasvind te midde van multikulturaliteit, waar gevestigde strukture plek moet maak vir spontaneïteit (Larkin, 1979:55). Hierby sluit Bhabha (1990:301) aan as hy liminaliteit gebruik om te verwys na multikulturele ontmoetings, waar die probleem nie meer dié is van "ander mense" nie, maar van 'n vraag oor die andersheid van mense as 'n eenheid.

Bain (2003:204) se bespreking dui aan dat liminaliteit inherent 'n konsep is wat dubbelsinnigheid en improvisasie behels en spesifiek relevant is vir jongmense. Hier kan die verband raakgesien word van die (dikwels) teatrale manier waarop jongmense praat en so hulle identiteit in eietydse verbuigings verwoord. Dentith (2000:2) beklemtoon dit as hy meen dat die taalgebruik van adolessente talryke parodieë oplewer wanneer hulle aksente van mense in hulle omgewing of die televisie en eietydse frase-giere naboots. Elkeen het 'n arsenaal van verbale en kulturele style wat hulle assimileer of verwerp.

Die studente in my navorsingsgroep het die ontwikkelingstaak om hulle identiteit te vind in die oorgangsruimtes wat hulle kultureel ervaar, want hulle leef in 'n soort niemandsland (vgl. Raybin, 1990:29) tussen jeug en volwassenheid, wit en bruin, Afrikaans en Engels, stad en platteland, manlik en vroulik, apartheid en 
postapartheid. Die skryf van parodietekste kan kreatief bydra tot die skep van wat Dawson (2005:166) noem:

... a hybrid form of writing known as fictocriticism ... discourse of a 'space between' the categories of fiction and criticism created by the epistemological collapse of critical distance in postmodern theory: a textual no-man's land in which a generic intermingling and hybridity of form takes place.

Die parodie aan die hand van ' $n$ bekende sprokie bied ' $n$ hibridiese skryfformaat waarbinne die studente hulle waarnemings van die mikrokosmos op die kampus, sowel as binne die groter SuidAfrikaanse kultuur, kan projekteer en omskep in 'n mosaïek van fiktiewe tekste. Met hierdie anonieme tekste en met behulp van satire kan hulle 'n eietydse kommentaar op hulle verweefde samelewing lewer. Die teks wat die studente te midde van hulle liminaliteit genereer, kan 'n antistrukturele rol speel in communitas. Laasgenoemde is Turner se term (Couldry, 2003:33) wat aandui dat die skrywer of kunstenaar deel is van 'n sosiaal-marginale groep; 'n term wat Raybin (1990:22,26) gebruik om te argumenteer dat kuns help om orde te skep in tye van sosiale chaos en diskontinuïteit, want

the work of art speaks in symbols and forms, and therefore speaks discreetly, generally nonthreateningly, often hiding the implications and power of its message. It may offer some blatant surface message, but such messages tend to longrange cultural insignificance.

Volgens Raybin (1990:31-32) kan kuns mense help om aan te pas, spanning te verlig en verandering teweeg te bring - juis omdat dit liminaal en buite gestruktureerde tyd en ruimte tot stand kom en bestaan. Bain (2003:197) gebruik liminaliteit in die konteks van haar artikel oor wit, Westerse, tienderjarige meisies in stede as ' $n$ palet van beperkte ruimtes waarbinne die adolessente kan terugtrek of in interaksie tree. Stevenson (1991:183) noem liminaliteit 'n grensgeval, 'n oorgangsverskynsel terwyl Ashley (1990:xviii) dit saadbeddings van kulturele kreatiwiteit noem.

Dit is dus juis in hierdie oorgangstyd waar dit gepas is om adolessente en jong volwasse studente aan te moedig om op kreatiewe wyse uiting te gee aan hulle konflikterende ervarings aan die een kant is hulle deel van 'n samelewing met nuwe norme waar alles gangbaar is, en aan die ander kant is daar tóg dinge waarteen hulle gekant is of nie self as ' $n$ lewenstyl sal kies nie. Die parodie bied aan hulle 'n lisensie om enigiets te sê binne die kode 
van dubbelstemmigheid, waar hulle hibridies-verweefde stories kan bydra tot die moontlikheid van 'n kulturele bewuswordings- en vernuwingsproses.

\subsection{Parodie en hibriditeit}

' $n$ Teoretikus wat baie bygedra het tot die begrip van die parodie as literêre teks, is Bakhtin (Rose, 1979; 1993; Hutcheon, 1985; Dentith, 2000). Binne die konteks van die skep van 'n humoristiese teks, word die konsep hibriditeit in hierdie artikel hoofsaaklik bespreek in die lig van Bakhtin se definisie daarvan (Shemtov, 2001:69):

It is the mixture of two social languages within the limits of a single utterance, an encounter, within the arena of an utterance, between two different linguistic consciousnesses, separated from one another by epoch, by social differentiation or by some other factor.

Volgens Bakhtin se bespreking van hibriditeit (Dawson, 2005:210) is dit duidelik dat die taal in fiktiewe tekste (soos die parodie) dubbelstemmig is, omdat elke woord terselfdertyd dié van die outeur se (literêre) taalgebruik is, én die taal van sosiale groepe en waardesisteme wat deel van 'n geordende heteroglossia ('n sosiaalgedeelde diskoers) uitmaak. Bakhtin se begrip van dialogiese verbeelding wat gemanifesteer word in die humor van die karnavaleske, is volgens Kehde (1991:27-29) sentraal in alle menselewens.

Verder identifiseer Bakhtin volksverhale as 'n uiters geskikte bron vir humor waarmee pretensies bespot kan word (McGlathery, 2001:119). Om sprokies kreatief met eietydse denke en kultuurpatrone te verweef, bied dus die moontlikheid van dubbelstemmigheid.

Die parodie bied die potensiaal om menigvuldige (moontlik ontoelaatbare) menings te vergestalt en in die proses van kreatiewe skryfwerk kan dit stemme vrymaak wat andersins in die openbaar as gevolg van ambivalensie onderdruk word. Satire forseer die skrywer en leser in die parodie om eensydige ernstigheid te kritiseer, juis omdat dit hoër genres en heersende diskoerse belaglik maak deur die proses van die karnavaleske (vgl. McGlathery, 2001:121-129).

Hibridiese tekste kan gesien word as kruis-kulturele kontaminasie, soos Bhabha (1994:38) opmerk dat die tussen-in (liminale) spasie die kulturele las van betekenis dra en bydra tot die artikulasie van kulturele hibriditeit. In die analise van die studente se parodieë is 
temas gevind wat getuig van hibriditeit en ek kon die veelvoudige kulturele en linguistieke tradisies onderskei soos dit in die parodieë verwoord word.

In die navorsingsproses is die parodieë van die studente spesifiek ontleed om te bepaal hoe die massamedia en eietydse kultuur hibridies in hulle stories verweef is. Die dubbelstemmigheid wat kenmerkend van die parodie is, het dus 'n kreatiewe uitlaatklep gebied waar studente agter 'n veilige masker kon staan om te sê wat dalk konfronterend is. Die portuurlesers het raakgesien hoe die skrywers binne die satiriese raamwerk van die parodie met 'n stem kon praat wat dalk andersins in die postmoderne samelewing op 'n nuwe manier gemarginaliseer word, want "alles is toelaatbaar en niemand mag iemand anders veroordeel nie" (woorde van 'n portuurleser).

\subsection{Parodie en postmoderniteit}

Omdat daar in die literatuur oor postmodernisme en parodie reeds uitvoerig deur veral Hutcheon (1985), Rose (1993) en Dentith (2000) geskryf is, sal in hierdie artikel net kortliks verwys word na die hooftrekke daarvan, soos dit van toepassing is op die navorsingsprogram. Meer spesifiek is dit opvallend hoe die studente se parodieë kommentaar lewer op die sosiaalkulturele kenmerke van die tyd en ruimte waarin hulle aan die begin van die 21ste eeu op Stellenbosch se universiteitskampus as deel van 'n massasamelewing lewe, waar omtrent al die eienskappe van 'n laat-kapitalistiese veranderlikheid en verbruikersmentaliteit hoogty vier.

Een van die kenmerke van parodie is dat dit kommentaar en kritiek lewer op fragmentasie, diskontinuïteit en 'n toenemende vlak van entropie wat kenmerkend is van die lewe in die postmoderne metropolis (Nünning, 1999:129). In die studente se parodietekste is aansienlik baie ooreenkomste tussen wat hulle in hulle stories verbeeld en wat geskryf is oor die parodieë in die laat negentiendeeeuse tydperk se uitbeelding van dekadensie (vgl. Hannoosh, 1989).

Daar is ook duidelike ooreenkomste in die studente se parodieë as 'n eietydse projeksie van hulle kulturele hibriditeit en kenmerke van die sogenaamde Generasie X/Y/Z se verbruikersmentaliteit (vgl. Sacks, 1996; Epstein, 1998; Herangi, 2002; Tulgan, 2000; Eaton, 2003; Grundling, 2003; Mokros, 2003; Ulrich \& Harris, 2003). Wanneer die studente se tekste later in die artikel in meer 
besonderhede bespreek word, sal daar meer uitgebrei word op hierdie kenmerke.

Die modernisme met sy elite-norme en konvensies oor wat aanvaarbaar was vir hoë literatuur erken nie eintlik die parodie as kunsvorm nie, veral as gevolg van die komiese en metafiksionele aspekte daarvan. In die postmodernisme is daarenteen 'n groter waardering vir die literêre waarde van die parodie en die bevraagtekening van waardes aan die hand van meta-narratiewe. Docker (Dentith, 2000:157) meen dat daar niks postmodernisties is aan die parodie nie. Volgens hom is dit eerder nou binne die postmodernisme moontlik om die rol van die parodie in populêre kultuur te waardeer op 'n manier wat modernisme se verbintenis tot sogenaamde hoë kultuur nie toegelaat het nie.

Die ironiese dubbelkodering wat in postmoderne literêre teorieë gangbaar is, kom na vore in die parodie se konvensies van die dekonstruksie van waardes. Dit vervang rasionalisme as verligtingsideaal. Hierdie verligtingsideaal was eie aan modernisme met ' $n$ nuwe neiging na eklektisisme en die teenstrydigheid van vorm en funksie. Daar is nie meer so 'n duidelike gaping tussen hoë en populêre kultuuruitings nie. Die parodie pas dus goed in by postmodernisme wat gekenmerk word deur nuwe hibriede bewegings en anti-rasionele, deelnemende teenkulture, met groter erkenning vir die gangbaarheid van relatiwiteit, toevalligheid, onbepaaldhede en selfs die absurde:

Its double coding accommodates the anxious sense of belatedness of exhaustion diagnosed by the critics of the postmodern as well as the hybridization and the ensuing sense of aesthetic replenishment extolled by the exponents of postmodernism (Bernard, 1999:167).

Dentith (2000:154) meen postmodernisme is op sigself 'n literatuur van selfparodie waarmee algaande met sigself gespot word. Hiermee word verwys na 'n beskouing wat simptomaties is van 'n algemene oortuiging dat postmodernistiese kulturele uitings gevul is met formele selfbewustheid, epistemologiese relativisme en parodie.

\subsection{Parodie as dialoog tussen kodes}

Die intratekstuele aard van die parodie-ontwerp dra daartoe by dat dit sowel openlik verweefd as dubbelstemmig is. Hiermee word bedoel dat die parodie ' $n$ dialoog tussen kodes impliseer (Ermarth, 1999:228), naamlik dié van die geparodieerde teks en dié van die parodieteks. Daar is dus 'n gesprek met die leser wat moet 
dekodeer dít wat deur die skrywer geënkodeer is. Die leser se verwagtings word gewek deurdat daar sinspeling op 'n ander (bekende) teks is. Die aanhalings en nabootsing wat ander tekste oproep, plaas die geparodieerde teks(te) in ironiese konflik met die leser se persepsie van wat in die parodie as geheel gebeur (Rose, 1993:34-35). Die onverwagse afbreking van lesersverwagtings gaan gepaard met die waarneming van inkongruensie en dit werk humor aan die hand. Cowart (1993:20) bespreek die effek wat die onvoorspelbaarheid van simbiotiese tekste het, en meen dat stilistiese kunsgrepe wat die verwagtings van lesers teleurstel of bedrieg juis die belangstelling in die teks behou, omdat dit die leser verhoed om self afleidings of voorspellings te maak en die teks daarom dalk slegs oppervlakkig lees.

Die emosies wat deur die parodie by die leser opgewek word, is in ooreenstemming met wat Vosloo (2003:70) van die satire sê: dit kan 'n vermenging van geamuseerdheid, ergerlikheid, veragting, walging en selfs haat wees. Die satire in die parodie wil die leser skok, na die waarheid dwing en na 'n gevoel van verset lei. Dentith $(2000: 2,3)$ bespreek ook hierdie houdings wat gepaard gaan met parodie as hy verwys na die register, styl en intonasie van die outeur wat in dialoog is met die leser in die vorm van 'n klag of onwillige toegewing, vurige of woeste instemming, verheerliking, ironie of persoonlike terughoudendheid. Irwin en Lombardo (2001:85) meen dat gehore (van visuele parodie) dit geniet om betrokke te wees in die kreatiewe (spelende) proses van dekodering.

Geskrewe parodieë kan verstaan word in terme van die kettings van diskoersuitings en die evaluerende houding wat gepaard gaan met elke deelnemer aan hierdie diskoers. Een van die aanwysers in geskrewe parodieë is spesifiek intertekstualiteit, waarmee die parodie sigself situeer in verhouding tot tekste wat dit voorafgaan, en waarna om die beurt weer verwys word deur tekste wat volg.

Genette (1997) maak verwysings na die literêre teoretici Kristeva en Rifaterre en bespreek intertekstualiteit (wat hy vroeër argitekstualiteit genoem het) intensief. Hy onderskei 'n verskeidenheid vorme van genres wat transtekstueel is en toon aan wat die verband tussen die epiese, tragiese, komiese en parodiese in die parodie is, soos gesien sedert Aristoteles (vgl. Genette, 1997:10, 18). Verder maak Genette 'n onderskeid tussen hipoteks (oerteks A), hiperteks (transformasie B van die oorspronklike teks A), parateks (titel, subtitel, intertitel, eindterm, voetnoot, voorwoord, epigraaf of opskrif, boekomslag, illustrasies en allografiese of outografiese invoeging in parodie B), en metateks (kommentare of resensies oor enige van 
die genoemde tekste). Hy noem dat die verskeie vorme van transtekstualiteit aspekte bevat van enige tekstualiteit, maar dat hulle ook potensieel tekstuele kategorieë is.

In bekwame kunstenaars se hande kan die parodie 'n instrument wees om die wêreld te herkonstrueer, juis omdat dit die (bekende) waardes en konvensies dekonstrueer en die leser daaraan kan deelneem (Ermarth, 1999:227). Rose (1979:128) bespreek Foucault se gebruik van parodietekste om kanonisiteit deur middel van selfrefleksiwiteit en metafiksionaliteit te relativeer. Self maak Rose 'n kritiese bydrae $(1979 ; 1993)$ deur die aandag te trek na die verdiskontering van lesersdekodering wat plaasvind in die lees van 'n parodie, omdat leesverwagtings verbreek word en aanpassings gemaak moet word. Die leser word dus uitgenooi om ondersoek in te stel, te evalueer en die hipotekstuele materiaal te hersitueer.

Cowart (1993:1) noem hierdie soort intertekstualiteit 'n epistemiese dialoog met vorige kodes wat lesers forseer om diachroniese verskille raak te sien in die simbiotiese verhouding met en tematiese hersiening van vorige literêre konvensies. In die laaste deel van die artikel (kyk 3.3) is die bedoeling spesifiek om verslag te lewer van die veelvuldige bewustelike (en selfs onbewustelike) maniere waarop die studente se parodietekste na sprokies en ander tekste verwys. Dit is 'n digte netwerk van aanhalings, verwysings, nabootsings, polemiese projeksies en beskouings wat deel uitmaak van die intertekstuele web waarin hulle met hulle eietydse samelewing spot.

Sowel die enkodeerder as die dekodeerder van parodietekste is in subjektiewe posisies (Hutcheon, 1985:86). Tog word die dubbelstemmigheid in die parodie in die lewe geroep deur die produsent wat die gegewens met 'n soort outoriteit manipuleer. Wat van intertekstualiteit in die algemeen en die parodie spesifiek geldig is, is die subjektiewe posisie van die skrywer as kontrolerende agent. Die skrywer se aksies van betekenisgewing is verantwoordelik vir die teks en daarom kan dit die hipoteties-hermeneutiese konstruk genoem word wat die leser se afleidings of interpretasies beïnvloed. Hutcheon $(1985: 88,94)$ meen in hierdie verband dat daar gepraat kan word van parodie as 'n beperkte of elitistiese literêre genre, juis omdat die produsent aanvaar dat die leser 'n gedeelde kulturele agtergrond sal hê en daarop inspeel.

Om aan te toon in watter mate die studente se parodietekste manifestasies van kulturele en intertekstuele hibriditeit is, bespreek ek vervolgens enkele van die parodieë soos wat dit ter sake is. 


\section{Studente se hibridies-verweefde tekste}

'n Opsomming van die inhoud van die studente se parodietekste is die volgende:

- Aspoester is in rymvorm en handel oor 'n meisie van Distrik Ses wat trou met Mandela se kleinseun.

- Asp*\#"tertjie bly saam met haar twee gay broers in Seepunt en word deur 'n genie gehelp om na die Mother City Queer Project te gaan.

- Die blonde bom van Benoni raak deurmekaar met die Aardige Adonis van Hillbrow en het die taak om die ryk Bodemloses se huis te verwoes. Sy word die nuwe mev. Bodemloos nadat die vorige een met haar fiksheidsinstrukteur verdwyn het.

- Gouelokkies en die drie bere handel oor die 18-jarige meisie van Hartebeesfontein wat in Gauteng haar onskuld verloor en 'n nuwe naam kry (Penelope), gearresteer word en uiteindelik met die trein terug huis toe geneem word.

- O, Griet! Skryf 'n parodie bestaan uit twee stories (Grietjie en Hansie en Die storie van die twee vuil kinders). ${ }^{1}$ Dit is veral eersgenoemde wat die studentelewe uitbeeld waar Grietjie 'n eerstejaarstudent is, en Hansie haar patetiese broer. Hulle gaan oudergewoonte en dronk ná hulle laatnaggekuier in die dorp na die McDonalds by die BP-stasie om hulle hongerpyne te stil.

- Rap-ons-nie / oor geld nie en sing ons van blomme? speel in die Middeleeue af en handel oor 'n rewolusionêre bevryding van slawe en die werkskepping wat die hoofkarakters Rablomsie en Katak met hul rap-ons-nie?-bleskopprodukte bewerkstellig.

- Repel steel nie se hoofkarakter is Patricia wat moet sing om koning Phantom tevrede te stel. Sy word deur 'n genie se pilletjies gehelp om die vloek wat op die koning rus met haar goue stem te verbreek. Uiteindelik het sy nie nodig om weer vir Gevorderde Haarstudio's te gaan werk nie.

- Die Suid-Afrikaanse weergawe van Sneeuwitjie speel af in die Afpadheidsjare en bekende politieke karakters is die hoofspelers. Straatkinders help haar om te oorleef en uiteindelik red Nelsin 
Madiba haar lewe nadat hy mond-tot-mond-asemhaling op haar toegepas het.

- Sneeuwitjie is bleekmooi en haar stiefma kan nie vir Bobergplaas 'n erfgenaam gee nie. Uiteindelik gaan Sneeuwitjie na Gauteng en help die straatkinders om die Lotto te wen met haar stiefma se towerspieël wat die nommers reg voorspel. Daarna trou sy met die maatskaplike werker wat die straatkinders versorg.

- Patruschka de la Blondé kom in die huis van die De Beergesin in nadat sy hulle sekuriteitswag om haar pinkie gedraai het. Hierdie storie lyk soos 'n tydskrifverhaal en die intrige het nie 'n einde nie, omdat dit die belofte het dat dit voortgesit sal word in die volgende week se aflewering.

- Hansie en Pietie is 'n retoriese vraag op rymvorm wat handel oor die skok van tannies oor "Hansie en Pietie wat saam lê" en nie meer hou van "meisies so fyn" nie.

- Aspoestertjie is 'n feeverhaal waar die hoofkarakter vlerke van 'n skoenlapper kry om uit haar lewe van armoede te styg. Haar stiefsusters skeur uit afguns haar vlerke af; die goeie fee maak haar lyfie daarmee toe, en dit "is hoe seringbloeisels in die wêreld gekom het".

- Rooihuid in Matieland is 'n spel met die name van manskoshuise in Stellenbosch. Dit word 'n avontuurverhaal waar die jong rooihuide moet soek na die prinses wat ontvoer is.

Soos dit uit die opsomming blyk, het nie al die studente se stories parodietekste geword nie. Enkele parodieë word bespreek namate kenmerke van verwante vorme van die parodiestyl na vore kom.

\subsection{Studente se tekste as verwante vorme van parodieë}

Om vrae op te stel vir die skrywers en portuurlesers van die parodieë, is veral gebruik gemaak van Shipley (1972), Grové (1976), HAT (1981), skrywers in Cloete (1992) en Vosloo (2003) se beskrywing van die verskillende verwante vorme van die parodie, naamlik die burleske, melodrama en pastiche.

Die meeste van die studente se parodietekste vertoon duidelike kenmerke van spesifiek die burleske (Grové, 1976:17), met klugtige, komieklike voorstellings waar spottend-ironiese nabootsings op so 'n wyse voorkom dat die banale en alledaagse oordrewe groots en belaglik aandoen. Volgens Genette (1997:22) is veral die burleske meer geneig tot die groteske. Voorstellings van karakters in sprokies 
word op 'n karikatuuragtige wyse nageaap spesifiek in Grietjie en Hansie. Hierdie storie toon selfs tekens van die groteske waar studentebedrywighede lagwekkend met sterk sardoniese en satiriese trekke uitgebeeld word. 'n Bekende wêreld word vanuit 'n perspektief betrag wat dit eensklaps vreemd laat voorkom, met komiese en tog vreesaanjaende gevolge.

Ook Hansie en Pietie en die twee Aspoester-parodieë is ligte spot met oënskynlik alledaagse homoseksuele en prostitusiepraktyke in Seepunt en Distrik Ses onderskeidelik. Dit is tekste waarin maklik herkenbare trekke van die karakters tot bespotlike proporsies oordryf word, met 'n satiriese effek. Die karakters word hoofsaaklik as karikature uitgebeeld (vgl. Felstiner, 1973:135-138; Grové, 1976:53) en daar is 'n voorstelling van persone en voorwerpe in komieklike situasies. Hierdie deel van die samelewing word met oordrewe effek spottend-hekelend afgebeeld deur middel van vergroting, oorbeklemtoning en oorvereenvoudiging.

Sowel Repel steel nie, die drie Gouelokkiestekste, en die Raponsiestorie is goeie voorbeelde van melodrama (vgl. Conradie, 1992:285; Rem, 1996; 1997). Dit is verwerkings van die oorspronklike sprokie waar die karakters stereotiep is en weinig kompleksiteit toon. Die intrige het baie uiterlike handeling met sensasionele insidente wat losweg aanmekaar gevoeg is. Klem word gelê op patetiese aspekte en skouspelagtige effekte word oordryf. Daar is 'n duidelike strewe om op die gevoelens van die leser te speel en emosies te ontlok.

Die twee Sneeuwitjie-parodieë is albei voorbeelde van pastiche (vgl. Pretorius, 1992a:370; Shipley, 1972:299) - dus samevoegings van uiteenlopende elemente ter wille van die satiriese effek. Dit is veral Die Suid-Afrikaanse weergawe van Sneeuwitjie wat 'n grappige omwerking is van die oorspronklike storie. Baie stereotipes word gebruik om die kultuur van Suid-Afrika duidelik te maak (spesifiek houdings teenoor die teenoorgestelde geslag, geloof, romantiese liefde). Volgens die parodieskrywer self word die storielyn van Sneeuwitjie behou sodat die leser kan weet wat om te verwag, maar die inhoud word op 'n bespottende wyse ingevul, sodat die leser nie verveeld sal raak nie. Hierdie beskouing van die storie pas by wat Genette (1997:22) stel, naamlik dat ware parodie en die bespottende nabootsing van die epiese pastiche ooreenstem daarin dat hulle 'n proses volg waarin 'n lae subjek ingevoer word, sonder dat daar met die verhewenheid van die oorspronklike storie gespot word. 
Satriese ontleding en ontlening geskied in albei die Sneeuwitjiestories op so ' $n$ wyse dat die geleende elemente nie struktureel opgaan in die nuwe verband nie. Die tekste stem ooreen met dít wat Pretorius (1992a:370-371) 'n lapwerk noem en bestaan uit die aanmekaar-"lym" van 'n mengelmoes beelde en episodes wat oorgeneem is uit verskeie geskiedkundige en eietydse kontekste. Die skrywers het wel die oorspronklike kunswerk vlytig herskryf met karikatuuragtige oordrywing.

Vervolgens sal aangetoon word in watter mate enkele van die studente se parodieë duidelike tekens dra van intertekstualiteit, heterogeneïteit, uitspattigheid wat herinner aan Bakhtin se begrip van die karnavaleske, en in 'n sterk verhouding staan tot die massamedia en lokale kultuurmanifestasies (homoseksualiteit, brassery en tipiese handelsmerke as populêre "kitsch" van 'n verbruikersamelewing).

\subsection{Kulturele temas}

\subsubsection{Die invloed van massamedia en 'n verbruikersamelewing}

Die televisie en elektroniese media is sedert 1975 belangrike kultuurskeppers in Suid-Afrika; dit vervang enersyds moontlik die voorheen sentrale magsposisie van mites, en veroorsaak andersyds die sogenaamde Generasie X/Y/Z-verskynsel - jeugdiges wat tipiese verteenwoordigende deelnemers (en dikwels slagoffers) van laat-kapitalisme en 'n verbruikersmentaliteit is (vgl. Annesley, 1998; Mokros, 2003). Hierdie media-rituele is egter volgens Couldry (2003:32-33) nie tipiese uitbeeldings van liminaliteit nie, omdat dit nie meer verpligte sosiale aktiwiteite is soos in Turner (Couldry, 2003:42) se siening van die konsep van primitiewe samelewingsrituele nie, maar wel 'n nuwe soort "gesellige samesyn" wat mense met mekaar deel, 'n meganies-gedrewe solidariteit. Studente se parodieë dekonstrueer media-rituele sowel as sprokies se ideologies-simboliese waardes en verwoord op hierdie manier 'n eiesoortige dubbelstemmigheid en intertekstualiteit.

'n Hele paar van die parodieë maak duidelik melding van die volgende elemente: materialisme (luukse wonings en klere, die Lotto), films (The Trueman Show, Brother Bear, Phantom of the opera, Lion King, Robin Hood), TV-sepies en programme (Days of our lives, Egoli, 7de Laan, Top Billing, Belboks, Blonde Sensasie), en advertensies van populêre produkte wat deel uitmaak van die 21ste-eeuse verbruikersamelewing (Sunsilk-sjampoe, inkopiesentrums, playstation-speletjies, MAC-grimering, Versace-ontwer- 
persklere, Jimmy Choo-skoene, Prozac-antidepressantgebruik van ryk vroue, Mercedes Benz-, Porsche- en BMW-motors, Fat Attack, Sure Slim, Kulula-lugdiens, ADT-sekuriteitsdienste, Men's Healthtydskrif).

Die parodietekste wat volgens die outeurs én portuurlesers tekens van dekadensie toon (vgl. Hannoosh, 1989:31-73), is veral Grietjie en Hansie (kyk 3.1.2), Die blonde bom van Benoni, Asp*\#"tertjie en in 'n mindere mate Repel steel nie. Dié stories is duidelike projeksies van 'n behoefte aan geluksaligheid, uitbeeldings van ongesonde en eksotiese lewenstyle, sedeloosheid, gebrek aan moraliteit en representasies van aanstellerigheid.

Die verband tussen dekadensie, 'n verbruikersmentaliteit en die studentekultuur is onmiskenbaar. Dit kan verklaar word deur Raybin (1990:29) se idee dat studente in 'n niemandsland van liminaliteit leef.

\subsubsection{Studentekultuur}

Die parodieë is 'n projeksie van eietydse studentekultuur: laatnag "kuierplekke", tipiese eerstejaardamestudente wat niks gewoond is nie, platvloerse skelwoorde wat blykbaar (volgens die portuurlesers) algemene studentetaal is, die kinderlikheid en onskuld waarmee menige student universiteit toe kom en vir die eerste keer met drank eksperimenteer.

'n Nuwe norm waarmee studente in die universiteitsamelewing toenemend moet saamleef, is die aanvaarding van homoseksualiteit. In die parodieë is daar ' $n$ uitbeelding van twee gaybroers en die Mother City Queer Project wat 'n groot sosiale geleentheid op homoseksuele mense se kalender is (Asp*\#"tertjie). Daar is ook homoseksuele verhoudings (Repel steel nie), die nuwe gier waar mans "saam lê" en "die tannies is geskok / oor die manne hou van stok" (Hansie en Pietie).

Benewens die uitbeelding van die studentekultuur is daar ook in die studente se parodieë heelwat verwysings na die polities-historiese milieu waarvan hulle deel is.

\subsubsection{Die Suid-Afrikaanse samelewing in postapartheid}

Een van die aspekte van die studente se liminaliteit waarbinne hulle hulself moet posisioneer om gestalte te gee aan 'n eie identiteit, is die feit dat hulle ouers het wat deel was van die apartheidsera se politieke sisteem in Suid-Afrika, terwyl die studente self dalk op 
skool reeds blootgestel is aan multikulturaliteit en postapartheid. Op universiteit is hulle deel van 'n postmoderne lewens- en wêreldbeskouing, waar alles "gangbaar" is (woorde van 'n portuurleser), aanvaar moet word en geen rassediskriminasie geduld word nie. Terwyl die meeste studente openlik apaties teenoor politiek staan, is die geskiedenis tog iets waarvan hulle kennis dra en sommige van hulle het ook gekies om dit as vak op skool te onderrig.

In twee van die parodietekste speel Mandela of sy sogenaamde kleinseun die rol van die prins wat die prinses sal red. Dit lyk asof die studente vir Madiba regtig as held beskou, maar aangesien hy reeds so oud is, kan hulle hom kwalik situeer as die jong, aantreklike prins. Een van die parodieë is spesifiek gesitueer in die "Afpadheidsjare" - 'n polities-georiënteerde verhaal wat basies die geskiedenis van Suid-Afrika in sprokievorm herskryf met blanke aktiviste, straatkinders, 'n sangoma se moetie, die reënboognasie en Madiba se kinderhuise.

Anders as in die twee vorige voorbeelde wat bespreek is, is in Rapons-nie / oor geld nie en sing ons van blomme? 'n meer pessimistiese (siniese) siening van die Suid-Afrikaanse kapitalistiese samelewing, waar die werkersklas nooit kan wen nie; waar "niebelangrike" grondeienaars wat 'n "eerlike, armoedige lewe gelei en gely" het, 'n nuwe toekoms van "vrye verslawing, geld en net genoeg brood" in die oë staar.

Die parodie wat die studentekultuur uitbeeld (Grietjie en Hansie) toon duidelik dat die wit studente se siening van swart mense nie noodwendig positief verander het sedert die koms van demokrasie in Suid-Afrika nie. Die heks in die storie is 'n cleaner wat laatnag in McDonald's werk en aan die einde van die parodie steel sy die "cash register leeg". Tydens die hele verhaal van 'n dronk roesemoes, werk die petroljoggies ongestoord voort, onbevange en apaties, dalk omdat dié soort voorval elke week herhaal word: "Die glasruit hy word elke week vervang en die studente hy is nie mooi."

Laasgenoemde aanhaling is een voorbeeld van Bakhtin se konsep heteroglossia wat in 'n student se parodie na vore kom. Vervolgens sal meer voorbeelde van hierdie sosiaal-gedeelde diskoerse (vgl. Dawson, 2005:209) aangehaal en in konteks beskryf word.

\subsubsection{Heteroglossia en kruiskulturele humor}

LaCapra (1983 - aangehaal in Ashley, 1990:xviii) meen Bakhtin se term karnavaleske is ideaal geskik om alle aspekte van die samelewing en kultuur deur middel van humor te toets en te evalueer. Dit 
wat 'n mens behoort te bevraagteken, word dan vir verandering voorberei, en dit wat as eg verklaar kan word, word bevestig en versterk. 'n Populêre kultuur, waarvan TV-sepies soos The Simpsons as populêre parodie (Knight, 2001:101) deel uitmaak, is 'n kultuuruiting wat aanhoudend die verskeidenheid en genot tussen mense van verskillende kulture deur middel van hulle verskillende diskoerse uitbeeld - kenmerkend van Bakhtin se begrip van die karnavaleske. Dawson (2005:209) meen letterkunde is essensieel 'n bewuste estetiese dramatisering van hierdie dialogiese samelewingsdiskoerse.

Voorbeelde van heteroglossia in die studente se parodieë kan gevind word in platvloerse skelwoorde van Grietjie en die skoonmaker se Xhosa (in hoofletters geskryf deur die outeur) wat deel uitmaak van 'n multitalige samelewing: "HAYI, WHAO! SUKA WENA! DIE KOMBUIS HY IS TOE! GA' HYSTOE! VOETSEK! DIE POLISIE, HY GAAN JULLE VANG! ... KUGQITHA." Die feit dat hierdie "vreemde taal" nie in die teks self vertaal word nie, veronderstel dat die verteller en die leser 'n agtergrondskennis deel. Die storie is ook vol Engelse sleng wat algemeen in die studente se taalgebruik is (vgl. Marais \& Coetzee, 2005).

Laasgenoemde parodie is waarskynlik die beste voorbeeld van dit waarna Vosloo (2003:70) verwys as hy sê dat die taalgebruik by satire gemene, smerige, brutale woorde, anti-literêre, plat omgangstaal, taboe-uitdrukkings en kru koeterwaals insluit. Die toonaard van die storie kan ook deur sommige lesers beskou word as banaal en vulgêr, grof en brutaal, amusant en sinies. Tog meen ek dat hierdie parodie in goeie smaak geskryf is, en alhoewel dit skokkend is om dit op skrif te sien (volgens die portuurlesers), is dit een van die beste stories wat studentekultuur uitbeeld, met uiters skerpsinnige humor, beeldspraak en woordspel.

In Asp*\#"tertjie is 'n interessante geval van kruiskulturele humor waar die gebruik van diakritiese simbole in die eienaam klem lê op die subversiewe - die leser sien en enkodeer die vloekwoord sonder dat dit ooit gesê is. Verder is daar in een van die Sneeuwitjieparodieë die spieël wat die onderdanige stem van 'n bruin plaaswerker gebruik en sê: "Ag, Noi weet mos Noi is die mooiste hier op die plaas."

Interessante voorbeelde van kruiskulturele humor kom na vore in die parodietekste waar die studente spot met die volgende Afrikaanse verhoog-, film- en televisiekunstenaars: Karen Zoid, Theuns 
Jordaan, Patricia Lewis, André Schwartz, Steve Hofmeyr, Kurt Darren en Charlize Theron.

Benewens die feit dat die studente se parodietekste kenmerke van verwante vorme van heteroglossia en kruiskulturele humor toon, is daar ook duidelike voorbeelde van dubbelstemmigheid waarmee die dialoog tussen enkodering en dekodering gemanipuleer is.

\subsection{Studente se tekste as dialoog tussen kodes}

In die ontleding van die kulturele temas in die studente se parodietekste het enkele voorbeelde na vore gekom van hulle intertekstuele verwysings en uitbreidings van idees wat kom uit Politically correct bedtime stories (Garner, 1994), Revolting rhymes (Dahl, 1982) en Kat se blad (De Vos \& Grobler, 1999). Daarbenewens is daar verwysings na 'n paar ander mites, legendes en sprokies as die oorspronklike tekste wat hulle as oertekste gebruik het (Adonis, Robin Hood, die paddaprins, Jan en die boontjierank, Liewe Heksie).

Ter sake is ook transtekstuele verwysings in die stories wat aansluit by Genette (1997:3) se uiteensetting van intertekstualiteit of argitekstualiteit. Voorbeelde van sulke paratekste word gevind in Grietjie en Hansie waar die subtitel "n Bos parodie" is. Dit is interessant dat Genette (1997:23) ook verwys na 'n soortgelyke parodie, naamlik "Parody of a forest" (Bois de Vincennes), iets waarvan die parodieskrywer waarskynlik nie bewus was nie. Die feit dat die twee woorde noukeurig apart geskryf word, dui op 'n doelbewuste dubbelsinnigheid - dié bos-parodie gee vir die leser 'n aanduiding van die omgewing waarin die storie afspeel, naamlik die populêre studentenaam vir Stellenbosch, en om "bos te wees" of "bos te gaan" beteken in studentetaal om "woes of wild of onbeskaaf' te wees. Verder is dit ook 'n verwysing na die oorspronklike teks (en baie ander sprokies) wat in die bos afspeel.

Dit lyk asof twee van die parodietekste deur middel van paratekste aanspraak maak op outentisiteit. Patrushka de la Blondé het 'n subtitel "Volume 1" en verwys aan die einde na die tweede volume van dieselfde reeks, terwyl die Asp*\#"tertjie-teks 'n voorwoord het: "[Konteks: Hierdie storie verskyn in Rooikappie en die drie wolwe en ander teleurstellende sprokies]". Daar is reeds vroeër gewys op die gebruik van diakritiese simbole in die eienaam om die subversiewe in Asp*\#"tertjie te beklemtoon en dit kan ook in hierdie verband gesien word as 'n voorbeeld van 'n allografiese parateks. 
Outografiese paratekstualiteit kom in die parodieë voor waar die skrywers tussen hakies 'n soort verduideliking gee of kommentaar lewer, waarskynlik om die leser te begelei in die dekoderingsproses en om te verduidelik wat bedoel word. In Grietjie en Hansie verduidelik die skrywer byvoorbeeld hóé laat dit is as hy sê "(Die son kom oor twee ure op en die Bos draai al klaar)", ook later as Hansie naar voel, is daar "(Veels te veel rosyntjiesap)". Dieselfde verskynsel kom voor in Rap-ons-nie / oor geld nie en sing ons van blomme? waar die outeur byvoorbeeld aan die begin vertel dat die storie lank terug afspeel "(seker doer in die middeleeue)" en dat Hekselina se blaf erger was as haar straf "(wel - vir die oomblik)". Ook Gouelokkies en die drie Bere se narratiewelyn word onderbreek met verduidelikings: Penelope gaan sit voor die televisie "(ook iets wat sy nog nooit gesien het nie)" en sy is nie gewoond aan so baie alkohol nie "(in der waarheid het sy nog nooit eers van so 'n woord gehoor nie)" - albei invoegings in die storie help om die meisie se naïwiteit te bevestig.

In die portuurlesers se lees van die parodietekste het die kwessie van gedeelde agtergrond juis na vore gekom. 'n Paar van die (spesifiek) bruin lesers het nie noodwendig dieselfde kulturele en literêre kodes met die meeste van die skrywers gedeel nie. Hulle het moeite gehad om die satire en ironie in die tekste te geniet as medeskeppers van betekenis. Dit was dus veral op ideologiese en generiese vaardigheidsvlak wat die paradigmatiese konteks van die enkodeerders en dekodeerders verskil het en 'n soort onbegrip of verwarring veroorsaak het.

Hiermee is dit duidelik dat daar baie potensiaal is in die skep van parodieë vir sowel skrywers as lesers, maar dat dit ook die gevaar inhou dat sommige lesers uitgesluit of geïsoleer kan word (veral in multikulturele kontekste) van die gunstige resepsie daarvan. Laasgenoemde hou verband met Hutcheon $(1985: 88,94)$ se siening van parodie as 'n beperkte of elitistiese literêre genre.

In verband met die dubbelstemmigheid wat 'n dialoog tussen outeurs- en leserskodes is, kan gemeld word dat daar wel by enkele lesers sekere vraagtekens was oor sekere invoegings en verdraaiings van die geparodieerde tekste wat hulle resepsie daarvan beïnvloed het. Dit sluit aan by wat Cowart (1993:26) sê, naamlik dat die enkodeerder die risiko loop om deur die leser gesien te word as literêr-onvolwasse en onoorspronklik. Die bevraagtekenings van die parodieë het wel getoon dat die lesers in sommige gevalle gemeen het dat die gasteks $B$ (in Genette se terme) minderwaardig is in terme van dit wat hulle bewonder in die oerteks $A$. Waarteen 
Hutcheon (1985:95) waarsku, gebeur dus meermale in hierdie parodieë, naamlik dat die leser nie snap wat die bedoeling van die outeur was nie, en dus nie die satire begryp nie. In albei gevalle waar dit in die resepsie-ondersoek voorgekom het, was bruin portuurlesers betrokke.

In twee gevalle het dit ook duidelik geblyk dat manlike portuurlesers dit nie geniet het dat daar soveel uitgebreide besonderhede in die storie voorgekom het nie, want "dit het die storie te lank uitgerek, dis te veel detail". Opvallend was dat dit telkens vroulike outeurs se stories is waarna verwys word. Ook het 'n paar vrouelesers beswaar gemaak teen die gekruide taal wat voorkom in die storie wat deur 'n manlike outeur geskryf is en dat dit hulle waardering daarvan negatief beïnvloed het. In al die gevalle is die stories anoniem aan die lesers voorgelê. Dit was interessant om op te merk dat hulle meestal korrek gehipotetiseer het oor die geslag en kulturele agtergrond van die outeurs. Laasgenoemde bespreking van kulturele verskille, ook tussen die humoruitings en resepsie van manlike en vroulike narratiewe, bevestig feministiese navorsingsgetuienis en besprekings van humor (Stillion \& White, 1987; Gagnier, 1988; Gillooly, 1991; Franzini, 1996; Kotthoff, 2000; Crawford, 2003).

\section{Gevolgtrekkings}

Parodie het die potensiaal om kritiese geletterdheid te ontwikkel en kreatiewe skryf te stimuleer by onderwysstudente wat Afrikaans as vak in sekondêre skole wil gaan onderrig. Behalwe dat die parodie 'n kreatiewe spel met grense is, kan dit ook 'n masker vir ambivalensie bied waar studente in liminale ruimtes beweeg. Parodie is 'n stylfiguur met die moontlikheid om seggenskap te gee aan marginale groepe. Terwyl daar gespot is met die swakhede en uitspattighede wat in die samelewing waarin die studente leef merkbaar is, het die parodie as literêre stylfiguur vir hulle die moontlikheid gebied om op kreatiewe manier hulle stem daaroor te verhef; waar hulle dalk andersins nie die moed sou hê om dit so direk te doen nie.

Die nut van die navorsingsprogram is dat dit die produsente sowel as die lesers daarvan krities laat kyk het na die samelewing, terwyl hulle implisiet ook besig is met selfrefleksie. Laasgenoemde is ' $n$ bewuswees van die self en die sosiale en literêre omgewings wat spesifiek binne die postmoderne tyd waarin die studente leef, gepas is. 
Bogenoemde bespreking van die temas wat na vore gekom het in parodieë wat die studente in die navorsingsprogram geskep het, toon duidelik dat hulle tekste meestal voldoen aan die kenmerke van parodie, soos bespreek deur Band (1990:179-180).

Die studente se parodieë het 'n intertekstuele digtheid getoon, met nabootsing en verwringing van die oorspronklike teks vir satiriese doeleindes. Parodieskrywers het 'n verskeidenheid stylmiddele gebruik, van dubbelsinnigheid en klankspel tot oordrywing, inkongruensie en verwysings wat 'n dubbele stel seine genereer naamlik een wat die oorspronklike teks oproep en die ander wat daarmee speel. Laasgenoemde het gebeur omdat die parodieskrywer met die oorspronklike teks se betekenis gespeel het, deurdat hy/sy daardeur aangetrek is, en tog ook daarvan wou ontsnap deur die waardes wat in die sprokies geënkodeer is te ondermyn. Die gevolg van hierdie spel was literêre kreatiwiteit, hoewel nie al die stories parodieë geword het nie.

Die parodiese teks het verwagtings by die leser geskep deurdat dit (deur middel van styl of implikasie) ooreenkomste getoon het met die oorspronklike sprokietekste, maar doelbewus hierdie verwagtings gefrustreer het, deur definitief verskillend daarvan te wees. Nie al die lesers was ewe beïndruk hiermee nie, maar dit het meestal bygedra tot baie kreatiewe energie en humor. Verder was die parodie slegs effektief indien die leser reageer op die dubbele stel seine wat teenwoordig daarin was. Nie alle lesers toon waardering hiervoor nie, en nie alle parodietekste was humoristies nie.

Terwyl die houding van die parodieskrywer oor die algemeen óf dié van simpatie óf oordeel kan wees, was dit in die studente se parodietekste meestal ambivalent. Die teiken van die parodieskrywers was meestal die ideologiese wêreld waarin hulle woon. As gevolg daarvan dat die parodieskrywer veronderstel het dat hy/sy die dubbele seine met die leser gedeel het, het daar 'n gedeelde diskoers, 'n episteem, ontstaan. Om hierdie rede het die parodie heelwat vrae aangaande 'n verskeidenheid norme en verwagtings deur die lesers se interpretasie laat ontstaan.

Hierdie program het baie potensiaal en het daarin geslaag om onderwysstudente toe te rus vir hulle onderrigtaak van Afrikaans as vak. Sommige van die geskrewe parodieë toon selfs moontlikhede vir verdere navorsing om die resepsie daarvan in die breër studentekorps vas te stel. Veral die verskil tussen vroue- en manshumor is in hierdie ondersoek nie voldoende ontgin nie. Dit sal 
moontlik kan lei tot meer bevindings en begrip van studentehumor en -kultuur.

\section{Geraadpleegde bronne}

ANNESLEY, J. 1998. Blank fiction: consumerism, culture and the contemporary American novel. New York: St. Martin's.

ASHLEY, K.M. 1990. Introduction. (In Ashley, K.M., ed. Victor Turner and the construction of cultural criticism: between literature and anthropology. Bloomington: Indiana University Press. p. ix-xxii.)

BAIN, A.L. 2003. White Western teenage girls and urban space: challenging Hollywood's representations. Gender, Place and Culture, 10(5):197-213.

BAND, A.J. 1990. Swallowing Jonah: the eclipse of parody. Prooftexts, 10: 177195.

BERNARD, C. 1999. The cultural agenda of parody in some contemporary English novels. European Journal of English Studies, 3(2):167-189.

BHABHA, H. 1990. Nation and narration. New York: Routledge.

BHABHA, H. 1994. The location of culture. Londen: Routledge.

BYBEL IN AFRIKAANS, 1936. Kaapstad: Britse \& Buitelandse Bybelgenootskap.

CONRADIE, P.J. 1992. Melodrama. (In Cloete, T.T., red. Literêre terme en teorieë. Pretoria: HAUM. p. 285-286.)

COULDRY, N. 2003. Media rituals: a critical approach. Londen: Routledge.

COWART, D. 1993. Literary symbiosis: the configured text in twentieth-century writing. Athens: University of Georgia Press.

CRAWFORD, M. 2003. Gender and humor in social context. Journal of Pragmatics, 35:1413-1430.

DAHL, R. \& BLAKE, Q. 1982. Revolting rhymes. Londen: Penguin Books.

DAWSON, P. 2005. Creative writing and the new humanities. New York: Routledge.

DE VOS, P. \& GROBLER, P. 1999. Kat se blad: stuitige strokies. Kaapstad: Human \& Rousseau.

DENTITH, S. 2000. Parody. Londen: Routledge. (The New Critical Idiom series.)

EATON, T. 2003. Culture? What is culture? (In Laugh it off. Annual. South African Youth Culture. Vol. 1. Kaapstad: Double Storey Books. p. 30.)

EPSTEIN, J.S. ed., 1998. Youth culture: identity in a postmodern world. Massachusetts: Blackwell.

ERMARTH, E.D. 1999. Finger exercises: parody as a practice for postmodernity. European Journal of English Studies, 3(2):226-240.

FELSTINER, J. 1973. The lies of art: Max Beerbohm's parody and caricature. London: Gollancz.

FRANZINI, L.R. 1996. Feminism and women's sense of humor. Sex Roles, 35(11/12):811-819.

GAGNIER, R. 1988. Between women: a cross-class analysis of status and anarchic humor. Women's Studies, 15:135-148.

GARNER, J.F. 1994. Politically correct bedtime stories. Londen: Souvenir.

GENETTE, G. 1997. Palimpsests: literature in the second degree. Lincoln: University of Nebraska Press.

GILLOOLY, E. 1991. Women and humor. Feminist Studies, 17(3). Elektronies beskikbaar: EbscoHost, Academic Premier. Date of access: 8 May 2005. 
GROVÉ, A.P., red. 1976. Letterkundige sakwoordeboek vir Afrikaans. Kaapstad: Nasou.

GRUNDLING, E. 2003. The koeksister guide to lekker Afrikaans. (In Laugh it off. Annual. South African Youth Culture. Vol. 1. Kaapstad: Double Storey Books. p. 42-43.)

HANNOOSH, M. 1989. Parody and decadence: Laforgue's Moralités legéndaires. Columbus: Ohio State University Press.

HERANGI, B. 2002. So, like, what's these Xers, man? (In Tiplady, R., ed. Postmission: world mission by a postmodern generation. Cumbria: Paternoster. p. 2-13.)

HUTCHEON, L. 1985. A theory of parody. Londen: Methuen.

IRWIN, W. \& LOMBARDO, J.R. 2001. The Simpsons and allusion: "Worst essays ever". (In Irwin, W., Conard, M.T. \& Skoble, A.J. The Simpsons and philosophy. Chicago: Open Court. p. 81-92.)

JOHNSTON, I. \& MANGAT, J. 2003. Cultural encounters in the liminal spaces of Canadian picture books. Changing English, 10(2):199-204.

KEHDE, S. 1991. Voices from the margin: bag ladies and others. (In Bauer, D.M. \& McKinstry, S.J., eds. Feminism, Bakhtin, and the dialogic. New York: State University of New York Press. p. 25-38.)

KNIGHT, D. 2001. Popular parody: the Simpsons meets the crime film. (In Irwin, W., Conard, M.T. \& Skoble, A.J. The Simpsons and philosophy. Chicago: Open Court. p. 93-107.)

KOTHOFF, H. 2000. Gender and joking: on the complexities of women's image politics in humorous narratives. Journal of Pragmatics, 32:55-80.

LARKIN, R. 1979. Suburban youth in cultural crisis. Oxford: Oxford University Press.

MARAIS, S. \& COETZEE, A. 2005. Tienerafrikaans. Tydskrif vir Taalonderrig, 39(2):244-259.

MCGLATHERY, D.B. 2001. The tomb of epic: Bakhtinian parody and Petronius' tale of the Widow of Ephesus. (In Barta, P.I., Miller, P.A., Platter, C. \& Shepherd, D., eds. Carnivalizing difference: Bakhtin and the Other. Londen: Routledge. p. 119-140.)

MOKROS, E.B., ed. 2003. Identity matters. New Jersey: Hampton.

NÜNNING, A. 1999. The creative role of parody in transforming literature and culture: an outline of a functionalist approach to postmodern parody. European Journal of English Studies, 3(2):123-137.

PRETORIUS, R. 1992a. Parodie. (In Cloete, T.T., red. Literêre terme en teorieë. Pretoria: HAUM. p. 370-372.)

PRETORIUS, R. 1992b. Satire. (In Cloete, T.T., red. Literêre terme en teorieë. Pretoria: HAUM. p. 464-465.)

RAYBIN, D. 1990. Aesthetics, romance and Turner. (In Ashley, K.M., ed. Victor Turner and the construction of cultural criticism: between literature and Anthropology. Bloomington: Indiana University Press. p. 21-41.)

REEVES, C. 1996. Students as satirists. College Teaching, 44(1). Elektronies beskikbaar: EbscoHost, Academic Search Premier. Date of access: 24 Aug. 2005.

REM, T. 1996. Melodrama and parody: a reading that Nicholas Nickleby requires? English Studies, 3:240-254.

ROSE, M.A. 1979. Parody/Meta-fiction: an analysis of parody as a critical mirror to the writing and reception of fiction. Londen: Croom Helm. 
ROSE, M.A. 1993. Parody: ancient, modern, and post-modern. Cambridge: Cambridge University Press.

SACKS, P. 1996. Generation X goes to college: an eye-opening account of teaching in postmodern America. Chicago: Open Court.

SHEMTOV, V. 2001. Metrical hybridization: prosodic ambiguities as a form of social dialogue. Poetics Today, 22(1):65-87.

SHIPLEY, J.T. ed., 1972. Dictionary of world literature. New Jersey: Littlefield Adams.

STEVENSON, S. 1991. Language and gender in transit: feminist extensions of Bakhtin. (In Bauer, D.M. \& McKinstry, S.J., eds. Feminism, Bakhtin, and the dialogic. New York: State University of New York Press. p. 181-198.)

STILLION, J.M. \& WHITE, H. 1987. Feminist humor: who appreciates it and why? Psychology of Women Quarterly, 11:219-232.

TULGAN, G. 2000. Managing Generation X: how to bring out the best in young talent. Londen: Norton.

ULRICH, J.M. \& Harris, A.L. 2003. GenXegesis: essays on alternative youth (sub) culture. Wisconsin: University of Wisconsin Press.

VAN DER MERWE, S. 2004. Generic engineering: a study of parody in selected works of Oscar Wilde, James Joyce and Tom Stoppard. Stellenbosch: University of Stellenbosch. (M.A. thesis.)

VAN GENNEP, A. 1960. The rites of passage. Londen: Routledge.

VERSTER, F. 2003. 'n Kultuurhistoriese ontleding van pikturale humor met besondere verwysing na die werk van T.O. Honiball. Stellenbosch: Universiteit van Stellenbosch. (D.Phil.-proefskrif.)

VOSLOO, J. 2003. Die manifestering van humor in geselekteerde Afrikaanse kortverhaaltekste. Stellenbosch: Universiteit van Stellenbosch. (D.Lit.proefskrif.)

Kernbegrippe:

heteroglossia

hibriditeit

intertekstualiteit

kruiskulturele humor

liminaliteit

parodie

postmoderniteit

studentekultuur

verbruikersamelewing
Key concepts:

consumer society

cross cultural humor

heteroglossia

hybridity

intertextuality

liminality

parody

postmodernity

student culture 